\title{
Fluoride Content in Alcoholic Drinks
}

\author{
Marta Goschorska $^{1}$ - Izabela Gutowska ${ }^{2}$ - Irena Baranowska-Bosiacka ${ }^{1}$ • \\ Monika Ewa Rać $^{1} \cdot$ Dariusz Chlubek ${ }^{1}$
}

Received: 29 June 2015 / Accepted: 23 September 2015 / Published online: 16 October 2015

(C) The Author(s) 2015. This article is published with open access at Springerlink.com

\begin{abstract}
The aim of the study was to determine the role of alcoholic drinks as a potential source of dietary fluoride by means of measuring fluoride levels in selected alcoholic drinks available on the Polish market that are also diverse in terms of the percentage content of ethanol. The study was conducted on 48 types of drinks with low, medium, and high alcohol content available on the Polish market and offered by various manufacturers, both Polish and foreign. Fluoride concentrations in individual samples were measured by potentiometric method with a fluoride ion-selective electrode. The highest fluoride levels were determined in the lowest percentage drinks (less than $10 \% v / v$ ethanol), with the lowest fluoride levels observed in the highest percentage drinks (above $40 \% v / v$ ethanol). In terms of types of alcoholic drinks, the highest fluoride levels were determined in beers and wines, while the lowest levels were observed in vodkas. These data confirm the fact that alcoholic beverages need to be considered as a significant source of fluoride delivered into the body.
\end{abstract}

Izabela Gutowska

gutowska@pum.edu.pl

1 Department of Biochemistry, Pomeranian Medical University, PowstańcówWlkp. av. 72, 70-111 Szczecin, Poland

2 Department of Biochemistry and Human Nutrition, Pomeranian Medical University in Szczecin, Broniewskiego 24 street, 71-460 Szczecin, Poland
Keywords Alcoholic drinks · Fluoride content · Fluoride intake

\section{Introduction}

The human body is constantly exposed to fluoride due to the consumption of food products, the main source of this element for humans [1, 2]. A significant part of this ingested fluoride is contained in beverages, including alcoholic drinks, a quantitatively significant component of the diet of many people and the primary source of exogenous ethyl alcohol [3]. Because of their prevalence and volume of consumption, they should be considered a potential source of other xenobiotics and taken into account in preparing a balanced diet [4]. Due to the continuing controversy over the use of fluorine compounds in the prevention of tooth decay and the possible adverse effects (fluorosis), it seems prudent to examine the presence of fluoride in common food products, including alcoholic beverages [5]. The small number of publications on the amount of fluoride in alcoholic beverages has led us to examine them as a possible source of fluoride in the diet.

The aim of the study was to determine the role of alcoholic drinks as a potential source of dietary fluoride by means of measuring fluoride levels in selected alcoholic drinks available on the Polish market that are also diverse in terms of the percentage content of ethanol.

\section{Material and Methods}

\section{Characteristics of Samples}

The study was conducted on 48 types of drinks with low, medium, and high alcohol content available on the Polish 
market and offered by various manufacturers, both Polish and foreign. The examined beverages were classified according to the percentage of ethyl alcohol:
1) $<10 \%$ of ethanol
2) $10-20 \%$ of ethanol
3) $20-40 \%$ of ethanol
4) $>40 \%$ of ethanol

Moreover, the alcoholic beverages tested for fluoride content were also classified in terms of the production process, namely: (1) vodka, (2) spirits with a high content of ethanol other than vodka, (3) rums, (4) liqueurs, (5) wines, and (6) beers.

\section{Determination of Fluoride Content in Collected Samples}

Fluoride concentrations in individual samples were measured by the potentiometric method with a fluoride ion-selective electrode (Orion 9409 BN, Thermo Scientific, USA). Carbonated drinks were degassed before the measurements $[6,7]$.

Samples of alcoholic beverages were collected directly from bottles, after thorough mixing of the contents.

To a 0.5 -ml solution sample, we added $0.5 \mathrm{ml}$ of TISAB II buffer, and after $5 \mathrm{~min}$ the potential of the samples was measured by potentiometry using an ion-selective electrode. Then, $0.1 \mathrm{ml}$ of the appropriate standard was added and measurement was performed again. The electrode had been calibrated using standard solutions.

According to the works of Gutowska et al. [8,9], the fluoride content in samples was calculated based on the difference of potentials measured in each sample and the concentration of the added standard. The electrode had been calibrated using standard solutions.

\section{Statistic Analysis}

For statistical analysis, nonparametric tests-Friedman ANOVA, Mann-Whitney $U$ test, and Spearman testwere used. All calculations were performed using Statistica 10.0 software (StatSoft Poland). Values of $p \leq$ 0.05 were considered statistically significant. Since in most of the publications results are given as mean value, our results were expressed as median (values in Table 1) and mean $\pm \mathrm{SD}$ (figures), so in the future those values may be used in various comparisons by other authors.
Table 1 Values of median and range of fluoride concentrations in the groups of drinks

\begin{tabular}{|c|c|c|c|}
\hline Alcohol & Median & Lower quartile & Upper quartile \\
\hline \multicolumn{4}{|c|}{ In dependence of percentage content of ethanol } \\
\hline$<10 \%$ & 0.131 & 0.103 & 0.172 \\
\hline $10-20 \%$ & 0.098 & 0.093 & 0.160 \\
\hline $20-40 \%$ & 0.056 & 0.034 & 0.110 \\
\hline$>40 \%$ & 0.044 & 0.037 & 0.072 \\
\hline \multicolumn{4}{|c|}{ In dependence of various kinds of alcoholic drinks } \\
\hline Vodkas & 0.044 & 0.036 & 0.049 \\
\hline Color vodkas & 0.050 & 0.041 & 0.073 \\
\hline Rums & 0.045 & 0.030 & 0.118 \\
\hline Liqueurs & 0.079 & 0.030 & 0.115 \\
\hline Wines & 0.105 & 0.094 & 0.199 \\
\hline Bears & 0.131 & 0.121 & 0.147 \\
\hline
\end{tabular}

\section{Results}

The highest fluoride levels were determined in the lowest percentage drinks (less than $10 \% v / v$ ethanol), with the lowest fluoride levels observed in the highest percentage drinks (above $40 \% v / v$ ethanol) (Fig. 1).

The fluoride levels in the alcoholic drinks with less than $10 \%$ and $10-20 \% v / v$ ethanol were statistically significantly higher than in drinks with $20-40 \%$ and above $40 \% v / v$ ethanol $(p<0.05)$ (Fig. 1).

In terms of types of alcoholic drinks, the highest fluoride levels were determined in beers and wines, while the lowest levels were observed in vodkas (Fig. 2).

Fluoride levels in both beers and wines were statistically significantly higher than the levels in vodkas $(p<0.05)$ (Fig. 2).

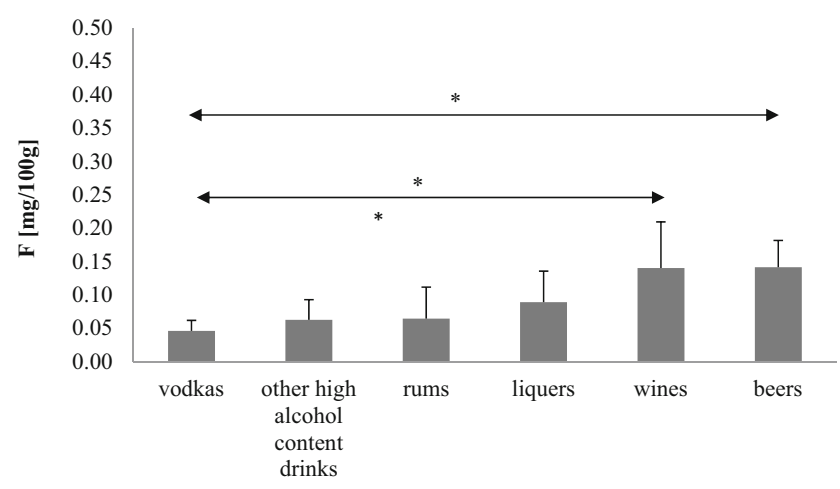

Fig. 1 The content of fluoride in various kinds of alcoholic drinks. ${ }^{*} p<0.05$ in comparison among each groups 




Fig. 2 The content of fluoride in various kinds of alcoholic drinks in dependence of percentage content of ethanol. ${ }^{*} p<0.05$ in comparison among each groups

Spearman's correlation analysis showed a negative significant correlation between the concentration of alcohol and fluoride content in beverages ( $\mathrm{rs}=-0.67, p=1.52 \times 10^{-07}$ ).

\section{Discussion}

According to the research of TNS OBOP (Polish Centre for Public Opinion Research), as many as $84 \%$ of the adult population in Poland consume alcohol, the majority of which are men. On a European scale, those who admit to alcohol consumption account for $76 \%$ of the population, while $24 \%$ are abstainers. In 2012, an average of 9.251 of alcohol was consumed per capita in Poland. Alcohol is most frequently consumed by people with higher education and urban residents, and beer is the alcohol of choice among Polish residents $(87.6 \%)$. Spirits are the second most widely consumed alcohol (7 \%), followed by wine http://www.tnsglobal.pl/ jakpijapolacy/pdf/raport.pdf.

In this study, alcohols from different brands available on the Polish market were examined. The fluoride levels correlated negatively with the levels of alcohol in beverages ( $\mathrm{rs}=$ $-0.67, p=1.52 \times 10^{-07}$ ). The highest concentration of fluoride was observed in the beverages with the lowest alcohol content $(<10 \%)$, while the lowest concentration was observed in the beverages with the highest percentage of alcohol. Having taken into account the type of alcoholic beverage, it became apparent that beer and wine had the highest levels of fluoride, while vodka and other spirits with a high content of alcohol had the lowest levels of fluoride http://www.tnsglobal.pl/ jakpijapolacy/pdf/raport.pdf.

The United States Department of Agriculture (USDA) data from 2004 show the lowest fluoride levels in spirits $(9 \mathrm{mg}$ / $100 \mathrm{~g}$ ), including vodka, rum, gin, and whiskey http://www. ars.usda.gov/SP2UserFiles/Place/12354500/Data/Fluoride/ F02.pdf. The same data shows higher levels of fluoride in regular beers $(44 \mathrm{mg} / 100 \mathrm{~g})$, lagers $(45 \mathrm{mg} / 100 \mathrm{~g})$, red wines $(105 \mathrm{mg} / 100 \mathrm{~g})$, and white wines $(202 \mathrm{mg} / 100 \mathrm{~g})$ http://www.ars.usda.gov/SP2UserFiles/Place/12354500/Data/ Fluoride/F02.pdf. However, subsequent studies show that the level of fluoride can vary in one given type or even brand, for example depending on the place of production [10]. Beer brands Heineken and Carlsberg, with licensed production in the UK, may serve as an example: they have lower fluoride levels compared with those brewed in Denmark and the Netherlands [10]. The differences in fluoride levels in beers have been explained as an effect of the different levels of fluoride naturally occurring in water or water fluoridation in some regions $[11,12]$.

It is difficult to compare our results with other studies, mainly due to the lack of publications on such a large group of alcohols and a large spread of the percentage in the test material. However, the obtained results are consistent with data published by the USDA. As for the values of the fluoride concentration in low-alcohol beverages, our results are similar to those obtained by Rees et al. in a low-alcohol drink made on the basis of lemonade and ethyl alcohol [13] and the research on the concentration of fluoride in wines from the Canary Islands $[12,14]$.

Fluorine is a ubiquitous element in the natural human environment. It is well known that its intake at an appropriate level is necessary to prevent tooth decay. However, an excessive intake of fluoride can result in serious consequences for human health. It is estimated that the daily intake of fluoride in the UK is approx. $1.82 \mathrm{mg}$ per day. It is noteworthy that more than $70 \%$ of the fluoride delivered into the body every day is contained in beverages, especially tea [12]. The excessive ingestion of fluoride in foods and drinks leads, i.a., to erosion of the enamel and, in consequence, to fluorosis [15]. These effects are observed in people who live in endemic fluorosis areas in China [16]. Recently, it was pointed out that groups of people who regularly consume alcohol should be taken into special consideration. According to a study carried out in the UK, alcoholics can consume large volumes of beer or cider per day, which means a weekly dose of more than 50 units [17]. The increased incidence of enamel erosion dependent on excess fluoride in a group of professional wine tasters is also reported $[18,19]$.

In summary the obtained results are difficult to interpret from the perspective of human health because of the differences in the fluoride level in these beverages depend on localization of manufacturing plants. Especially important is the content of fluoride in local water sources. But these data, as well as several reports by other authors, confirm the fact that alcoholic beverages need to be considered as a significant source of fluoride delivered into the body. 
Acknowledgments This study was supported by the statutory budget of the Department of Biochemistry, Pomeranian Medical University.

Open Access This article is distributed under the terms of the Creative Commons Attribution 4.0 International License (http:// creativecommons.org/licenses/by/4.0/), which permits unrestricted use, distribution, and reproduction in any medium, provided you give appropriate credit to the original author(s) and the source, provide a link to the Creative Commons license, and indicate if changes were made.

\section{References}

1. Li S, Smith KD, Davis JH, Gordon PB, Breaker RR, Strobel SA (2013) Eukaryotic resistance to fluoride toxicity mediated by a widespread family of fluoride export proteins. Proc Natl Acad Sci U S A 110(47):19018-19023

2. Li Y, Liang C, Slemenda CW, Ji R, Sun S, Cao J, Emsley CL, Ma F, Wu Y, Ying P, Zhang Y, Gao S, Zhang W, Katz BP, Niu S, Cao S, Johnston CC Jr (2001) Effect of long-term exposure to fluoride in drinking water on risks of bone fractures. JBMR 16(5):932-939

3. Greenfield TK, Kerr WC (2008) Alcohol measurement methodology in epidemiology: recent advances and opportunities. Addiction 103(7):1082-1099

4. Tekle-Haimanot R, Haile G (2014) Chronic alcohol consumption and the development of skeletal fluorosis in the fluoride endemic area of the Ethiopian Rift Valley. JWARP 6:149-155

5. Lakshmi V (2013) Fluoride intake, diet and health status of children residing in low endemic fluoride afflicted areas of Chittoor District. IJSER 1(4):2347-3878

6. Nicholson K, Duff EJ (1981) Fluoride determination in water: an optimum buffer system in use with the fluoride selective electrode. Anal Lett, Part A.: Chem Anal 14

7. Heilman JR, Levy SM, Wefel JS, Patterson KY, Cutrufelli R, Pehrsson PR, Holden JM (2006) Fluoride assay methodology for carbonated beverages. J Dent Child 73(3):136-139

8. Gutowska I, Baranowska-Bosiacka I, Szynkowska A, Siwiec E, Szczuko M, Noceń I, Rębacz-Maron E, Chlubek D,
Stachowska E (2012) Effect of supplementation with conjugated dienes of linoleic acid (CLA) on the content of fluoride, calcium and magnesium in the hard tissues and serum of mice. Fluoride 45:329-336

9. Gutowska I, Baranowska-Bosiacka I, Noceń I, Dudzińska W, Marchlewicz M, Wiszniewska B, Chlubek D (2011) Changes in the concentration of elements in the teeth of rats with type 1 diabetes, in the peak stage of the disease with absolute insulin deficit. Biol Trace Elemen Res 139:332-340

10. Warnakulasuriya S, Harris C, Gelbier S, Keating J, Peters T (2002) Fluoride content in alcoholic beverages. Clin Chim Acta 320(1-2): $1-4$

11. Schulz EM, Epstein JS, Forrester DJ (1976) Fluoride content of popular carbonated beverages. J Prev Dent 3(1):27-29

12. Martínez OB, Díaz C, Borges TM, Díaz E, Pérez JP (1998) Concentrations of fluoride in wines from the Canary Islands. Food Addit Contam 15(8):893-897

13. Rees JS, Burford K, Loyn T (1998) The erosive potential of the alcoholic lemonade Hooch. Eur J Prosthodont Restor Dent 6(4): 161-164

14. Rodriguez Gomez MI, Hardisson de la Torre A, Burgos Ojeda A, Alvarez Marante R, Diaz Flores L (2003) Fluoride levels in wines of the Canary Islands (Spain). Eur Food Res Technol 216:145-149

15. Lung S, Cheng H, Fu C (2008) Potential exposure and risk of fluoride intakes from tea drinks produced in Taiwan. J Expos Sci Environ Epidemiol 18:158-166

16. Ding Y, Gao Y, Sun H, Han H, Wang W, Ji X, Liu X, Sun D (2011) The relationships between low levels of urine fluoride on children's intelligence, dental fluorosis in endemic fluorosis areas in Hulunbuir, Inner Mongolia, China. J Hazard Mat 186:1942-1946

17. Harris CK, Warnakularsuriya KA, Johnson NW, Gelbier S, Peters TJ (1996) Oral health in alcohol misusers. Comm Dent Health 13: 199-203

18. Mok TB, McIntyre J, Hunt D (2001) Dental erosion: in vitro model of wine assessor's erosion. Aust Dent J 46(4):263-268

19. Amaral Cda S, Vettore MV, Leão A (2009) The relationship of alcohol dependence and alcohol consumption with periodontitis: a systematic review. J Dent 37(9):643-651 